\title{
Hypopharyngeal Cancer pT2 TNM Finding v6 and v7
}

National Cancer Institute

\section{Source}

National Cancer Institute. Hypopharyngeal Cancer pT2 TNM Finding v6 and v7. NCI

Thesaurus. Code C64450.

Hypopharyngeal cancer with tumor invading more than one subsite of hypopharynx or an adjacent site, or with tumor size more than 2 centimeters, but not more than 4 centimeters in greatest dimension without fixation of the hemilarynx. (from AJCC 6th and 7th Eds.) 